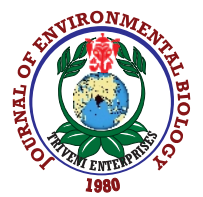

\title{
Toxicity of gold nanoparticles on the survival and hatching rates of African catfish (Clarias gariepinus) embryo and larvae
}

\author{
K. Marimuthu', R. Subramaniam ', B. Lertanantawong', S.Y. Lee', J.F. Borgio ${ }^{3}$, S.M.N. Amin ${ }^{4,5}$, S. Abdul Azeez ${ }^{3}$, M.A. Rahman ${ }^{6}$ \\ and A. Arshad ${ }^{4 *}$ \\ 'Department of Biotechnology, Faculty of Applied Sciences, AIMST University, Bedong, 08100, Malaysia \\ ${ }_{2}^{2}$ Pilot Plant Development and Training Institute, King Mongkut's University of Technology Thonburi, Bangkok, 10150, Thailand \\ ${ }^{3}$ Department of Genetic Research, Institute for Research and Medical Consultation (IRMC), Imam Abdulrahman Bin Faisal University, Dammam, \\ 342217176, Saudi Arabia \\ ${ }^{4}$ Department of Aquaculture, Faculty of Agriculture, Universiti Putra Malaysia, 43400 Serdang, Selangor, Malaysia \\ ${ }^{5}$ FAO World Fisheries University, Pukyong National University, Nam-gu, Busan 48547, South Korea \\ ${ }^{6}$ Department of Fisheries and Marine Bioscience, Faculty of Biological Science and Technology, Jashore University of Science and Technology, \\ Jasore, 7408, Bangladesh \\ *Corresponding Author Email : azizarshad@upm.edu.my
}

\begin{tabular}{lll}
\hline Paper received: 21.12 .2019 & Revised received: 17.02 .2020 & Accepted: 14.08 .2020 \\
\hline
\end{tabular}

\begin{abstract}
Aim : African catfish (Clarias gariepinus) was selected model organism in this study to investigate the toxic effects of gold nanoparticles (AuNPs) on its embryonic and larval development.

Methodology : Mortality, hatching rate and malformation of $C$. gariepinus embryo and larvae exposed to AuNPs were observed and recorded.

Results : The study found that as AuNPs concentration increased, the embryo's hatching rate and larvae's survival rate decreased. A higher concentration of AuNPs $\left(>10 \mathrm{mg} \mathrm{l}^{-1}\right)$ induced toxicity in fish embryo. In contrast, exposure to AuNPs induced embryonic malformations such as pericardial edema, yolk sac edema, neck, and head defects.

Interpretation: The results obtained in the study provides additional details with the present understanding of possible ecotoxicological effects of AuNPs and reinforce to closely monitor the release of AuNPs into the aquatic environment.

Key words: African catfish, Clarias gariepinus, Embryo toxicity, Gold nanoparticles

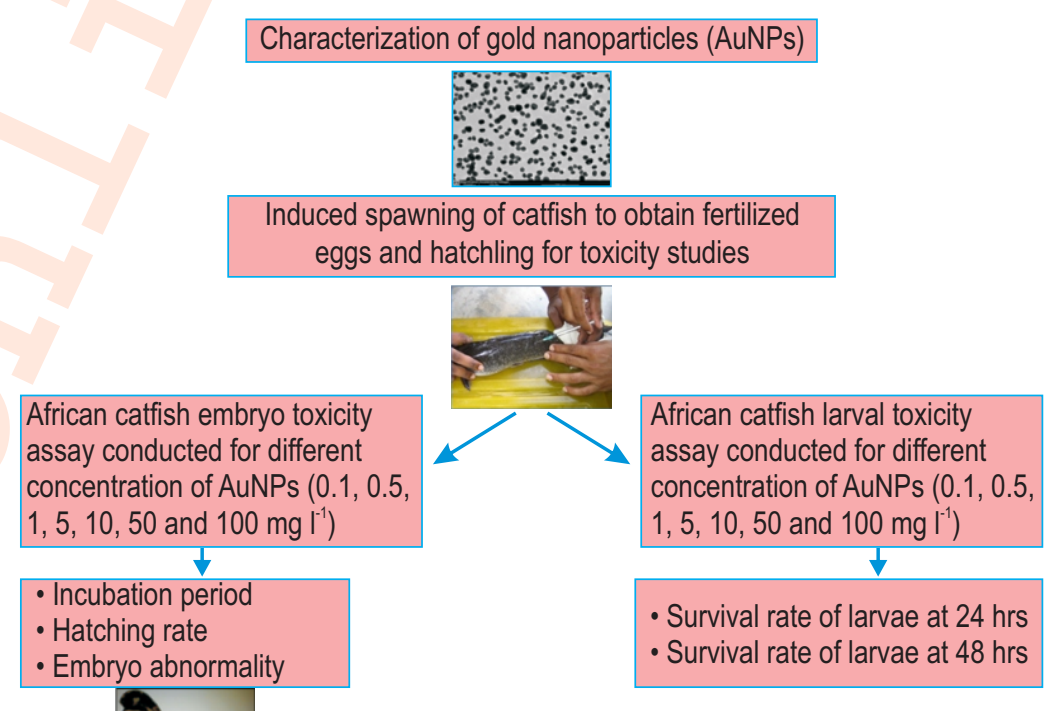

How to cite : Marimuthu, K., R. Subramaniam, B. Lertanantawong, S.Y. Lee, J.F. Borgio, S.M.N. Amin, S. Abdul Azeez, M.A. Rahman and A. Arshad: Toxicity of gold nanoparticles on the survival and hatching rates of African catish (Clarias gariepinus) embryo and larvae. J. Environ. Biol., 41, 1179-1185 (2020). 


\section{Introduction}

The rapid advancement in the field of nanotechnology has extended its applications into various fields, including electronics, optics, textiles, biomedical, and environmental remediation (Oberdorster et al., 2005; Shen et al., 2014). Due to increase in the surface-to-volume ratio, nanoparticles show unique physical-chemical and high specific surface properties. Bulk gold is considered inert, but at the scale of nanoparticles, gold has completely different properties due to its surface resonance excitation characteristics (Aillon et al., 2009; Jenkins et al., 2013; Marsich et al., 2011). The widespread use of gold nanoparticles (AuNPs) are due to simple synthesis protocol, external surface modifications (covalent) (Khlebtsov and Dykman, 2011; Lewinski et al., 2008; Longmire et al., 2008), easily modified surface charges (Longmire et al., 2008), extreme resistance to oxidation (Longmire et al., 2008) and fast detection (Fadeel and Garcia-Bennett, 2010). Numerous methods can be used to detect AuNPs, such as fluorescence microscopy, differential interference contrast microscopy, transmission electron microscopy (TEM), optical microscopy, optical coherence tomography, photoacoustic imaging, X-ray scattering, multiphoton surface plasmon resonance microscopy, two-photon luminescence, polarized resonance scattering and gamma radiation using neutron activation (Boisselier and Astruc, 2009; Khlebtsov and Dykman, 2011). In addition, AuNPs have many desirable optical properties, including photobleaching resistance (Fadeel and Garcia-Bennett, 2010), easily adjustable surface plasmon absorption and dispersion (vis-NIR) (Khlebtsov and Dykman, 2011; Longmire et al., 2008) and extreme nano-sized light dispersion (Fadeel and Garcia-Bennett, 2010).

At present, AuNPs are used to strengthen solar cells and act as flash memory devices in liquid crystal form (Prime et al., 2009; Tsoukalas, 2009). It has several applications in the biomedical field, including drug delivery, gene therapy, photothermal and radiotherapy, biosensing as well as cancer contrast agents, diagnostic tracers, enzyme immobilization and cell imaging. (Bracamonte et al., 2011; Chandra et al., 2010; Li et al., 2011; Nimesh, Gupta and Chandra, 2011; Pissuwan et al., 2011; Zhang et al., 2010). Other applications include purification of water and hydrogen, pollution control and carbon monoxide oxidation catalysts (Hashmi and Hutchings, 2006; McPherson and Thompson, 2009; Sardar et al., 2009). Notwithstanding their enormous potential benefits in ecological, biomedical and industrial applications, data on the impact of AuNPs on aquatic organisms and environment is meagre. Previous studies have reported that AuNPs circulate in the body for an extended period of time without being rejected by the immune system of the body. Health and safety information on the use of AuNPs is currently limited, while gold as a component is generally considered inert and biocompatible (Longmire et al., 2008). The toxicological effects of AuNPs are poorly understood. However, few researchers have raised concern about toxicity of nanoparticles, including AuNPs (Almeida et al., 2011; Dreaden et al., 2011). Because of these issues, AuNPs toxicity in non-target species and environment needs to be studied in depth.

As AuNPs are readily taken up by the cells, they are used as new tools in medical diagnostic research and drug delivery systems (Azzazy and Mansour, 2009; Chithrani et al., 2006; Yih and Al-Fandi, 2006). Several studies have reported the cytotoxic effect of different sizes and coating properties of AuNPs. Pan et al. (2007) reported that smaller AuNPs are more toxic. Connor et al. (2005), on the other hand, found no toxic effects on AuNPsexposed human leukaemia cell lines. Adverse effects of cytoskeletal components and decreased cell growth in human dermal fibroblasts along with increased levels of reactive oxygen in exposed bivalves have been reported (Pernodet et al., 2006; Tedesco et al., 2008). The cytotoxicity of AuNPs in human cells has been elucidated and the findings have shown that they are non-toxic up to $250 \mathrm{mM}$, while ionic gold demonstrated detectable cytotoxicity at $25 \mathrm{mM}$ (Connor et al., 2005). The earlier studies did not investigate the toxicity of AuNPs (4-18 nm in diameter) with respect to cell viability, pro-apoptotic effects, oxidative stress, and inflammatory response (Connor et al., 2005; Khan et al., 2007; Shukla, 2005). Brandenberger et al. (2010) confirmed that nonfunctionalized 13-20 nm-diameter gold particles do not cause immediate adverse effects. Very few toxicological reports and data are available on the toxicity of AuNPs in animal models, especially aquatic organisms. Hence, this study was carried out to investigate the possible toxic effects of various concentrations of AuNP on the African catfish embryo and larvae. Embryo and larvae stages are considered as the most vulnerable stage in the life cycle of fish contaminants (Westernhagen, 1988). This is valuable for examining the toxicity of any chemicals that could impact the environment and human health (Fraysse et al., 2006; Zhu et al., 2008). The findings of this investigation will contribute to the recent understanding of nanoparticles ' toxicological consequences, supporting the safe use of nanomaterials and protecting the aquatic environment.

\section{Materials and Methods}

AuNPs synthesis and characterization : Gold nanoparticles (AuNPs) were prepared following the sodium citrate reduction method (Turkevich et al., 1951 and Frens, 1973). Two hundred $\mathrm{ml}$ of $0.01 \%$ hydrogen tetrachloroaurate $\left(\mathrm{HAuCl} 4.3 \mathrm{H}_{2} \mathrm{O}\right.$, Sigma) in water was vigorously stirred and heated to boil. In the reaction mixture, sodium citrate ( $1 \%$ in aqueous solution) was added and boiled. The light-yellow colour solution completely changed its color to deep blue and eventually red wine after one minute. The reaction was stopped after boiling the solution for $5 \mathrm{~min}$. The total volume of the reaction mixture was then adjusted to $200 \mathrm{ml}$ and stored at $4^{\circ} \mathrm{C}$ for further use. The AuNPs synthesized were characterized using a 350 to $800 \mathrm{~nm}$ wavelength UV-VIS spectrophotometer (DU8000 Beckman Coulter, USA). The size of AuNPs was measured by transmission electron microscope 
(JEM-2100, JEOL Ltd., Japan).

Maintenance of brood fish: This study was carried out at the Aquaculture Research Facility, AIMST University, Kedah Darul Aman, Malaysia. Circular cement tanks were filled with tap water and stored for $48 \mathrm{hr}$ before prior to experiments to remove the chlorine present in the water. Sexually mature male and female African catfish, weighing $1-2 \mathrm{~kg}, 40-50 \mathrm{~cm}$ were purchased from the local fish market in Sungai Petani, Kedah Darul Aman, Malaysia. Brood fish were acclimatized at $28^{\circ} \mathrm{C}$ under natural light conditions in $500 \mathrm{I}$ circular cement tanks.

Production of fertilized fish eggs: Based on the external morphological characteristics, two matured males and female fish were selected. Both female and male fish were intramuscularly administered with $0.4 \mathrm{ml}$ of Ovaprim $\mathrm{kg}^{-1}$ body. The eggs were stripped from the female fish after $12 \mathrm{hr}$ of latency period and the testes were surgically removed from the male fish. The stripped eggs were mixed with sperm suspension prepared from testis. The eggs were then stirred gently for 2 min and the eggs were washed twice with fresh water and transferred immediately for embryo toxicity assay to experimental containers. To collect hatchlings for larval toxicity tests, a part of the fertilized eggs were placed in a rectangular glass tank.

Embryo and larval toxicity studies: Embryo toxicity study was designed according to the standard guidelines of OECD (1998). Water quality parameters were determined by the methods described in APHA (2012), and their values are as follows: temperature $26.0 \pm 2.0^{\circ} \mathrm{C}, \mathrm{pH} 7.2 \pm 0.4$, dissolved oxygen $7.2 \pm$ $0.1 \mathrm{mg} \mathrm{l}^{-1}$, total alkalinity $\left(\mathrm{as} \mathrm{CaCO}_{3}\right) 27.0 \pm 2.0 \mathrm{mg} \mathrm{l}^{-1}$, hardness $32.0 \pm 5.0 \mathrm{mg} \mathrm{l}^{-1}$, nitrate $2.4 \pm 0.1 \mathrm{mg} \mathrm{l}^{-1}$, nitrite $0.01 \mathrm{mg} \mathrm{l}^{-1}$, ammonia $0.01 \pm 0.001 \mathrm{mg} \mathrm{l}^{-1}$ and chloride $6.2 \pm 1.1 \mathrm{mg} \mathrm{l}^{-1}$. Stock solution of AuNPs were diluted to concentrations of $0.1,0.5,1,5$, 10,50 and $100 \mathrm{mg} \mathrm{l}^{-1}$. Twenty-five fertilized eggs were placed in each Petri dish containing different concentrations of AuNPs. Fertilized eggs exposed to water were treated as control. Each control and treatment groups were performed in 3 replicates. The Petri dishes were covered with lids and placed in the ambient temperature and light conditions. Hatching time and number of dead embryos for both control groups and exposed AuNPs were recorded. Hatchlings in the control and AuNPs exposed groups were randomly selected immediately after hatching and again at $24 \mathrm{hr}$ after hatching. Embryos were tested for possible morphological deformities commonly found in toxicological studies under a microscope (Boudreau et al., 2004; Peters et al., 2007).

For larval toxicity study, hatchlings were placed in Petri dishes containing $0.1,0.5,1,5,10,50$ and $100 \mathrm{mg} \mathrm{I}^{-1}$ of AuNPs. Hatchlings exposed to water served as. Each control and AuNPs exposed groups were performed in three replicates. Petri dishes were examined after $24-48 \mathrm{hr}$ and the number of dead larvae was counted and recorded. Larvae were considered to be dead when they became enlarged, white, opaque and did not move even when agitated with a plastic rod.

Statistical analysis: The data presented in this study on embryo hatching and fish larvae survival rate is the average of three replicates \pm standard deviation (SD). The results were analyzed by One-way variance analysis (ANOVA) followed by Duncan multiple range test at $5 \%$ significant using version 20 of SPSS

\section{Results and Discussion}

Characterization of AuNPs : Characterization of AuNPs using transmission electron microscopic (TEM) images and size distribution is shown in Fig. 1. AuNPs were spherical in shape with diameter of $36.47 \pm 7.42 \mathrm{~nm}$. On adding AuNPs to water used for incubation and larval bioassay induced the formation of aggregates. The study revealed that the AuNPs aggregates settled in the water column rapidly. A coating of AuNPs aggregates was found at the bottom of all the exposed Petri dishes after an incubation period of $24 \mathrm{hr}$. The incubation media was clear and all the AuNPs aggregates were settled. UV-Vis spectra of citrate-stabilized AuNPs showed two different peaks that matched different particle shapes. Spherical-shaped AuNPs showed a single maximum absorption peak at $521 \mathrm{~nm}$, while urchin-shaped AuNPs showed maximum absorption at $695 \mathrm{~nm}$.

Mortality and hatching rate of embryos exposed to AuNPs: Table 1 demonstrates the toxicity of AuNPs to the viability of African catfish embryos. In the embryo toxicity assay, embryo mortality was increased by increasing the concentrations of AuNPs from 5 to $100 \mathrm{mg} \mathrm{l}^{-1}$, but these differences $(P>0.05)$ did not vary significantly between control and treatment groups. The incubation periods of fertilized eggs were determined as $25 \mathrm{hr}$ for both control and treated groups up to $10 \mathrm{mg} \mathrm{l}^{-1}$. The incubation period decreased slightly in treatment groups of 50 and $100 \mathrm{mgl}^{-1}$.

There was a slight increase in hatching at 1,5 and $50 \mathrm{mg} \mathrm{l}$ ${ }^{1}$ treatment and a decline in hatching at $100 \mathrm{mg} \mathrm{l}^{-1}$, but the difference was not significant $(P>0.05)$. The survival rate of embryos exposed to various AuNPs concentrations for $48 \mathrm{hr}$ showed a gradual decline as AuNPs concentration increased. The exposed embryo's decreased survival rate $(P<0.05)$ was significant compared to the control group. The results showed that the AuNPs-exposed embryos developed embryonic toxicity and dose-dependent mortality increased.

Survival rate of larvae exposed to AuNPs: The survival rate of catfish larvae was observed at 24 and 48 hrs post-exposure to AuNPs. After $24 \mathrm{hr}$ exposure, the survival rate decreased in all tested concentrations of AuNPs. Nevertheless, no significant difference was observed in the survival rate between the AuNPs concentration of $0.1-50 \mathrm{mg} \mathrm{l}^{-1}$. Significantly low survival of larvae $(16.7 \%)$ was noticed with $100 \mathrm{mg} \mathrm{I}^{-1}$ AuNPs exposed group. After $48 \mathrm{hr}$ of exposure, $32 \%$ of larvae survived at $0.1 \mathrm{mg} \mathrm{l}^{-1}$ AuNPs and 
(a) A

B
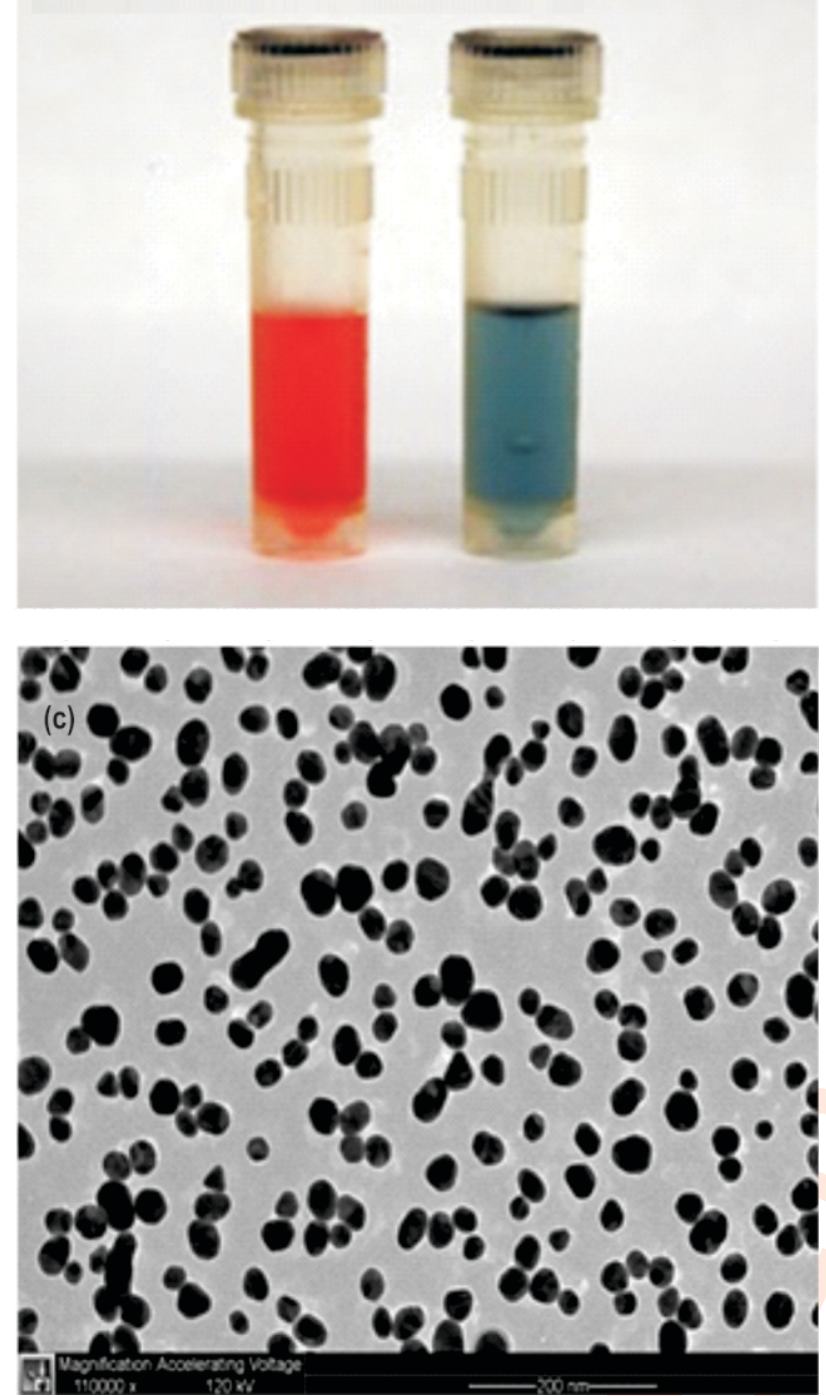
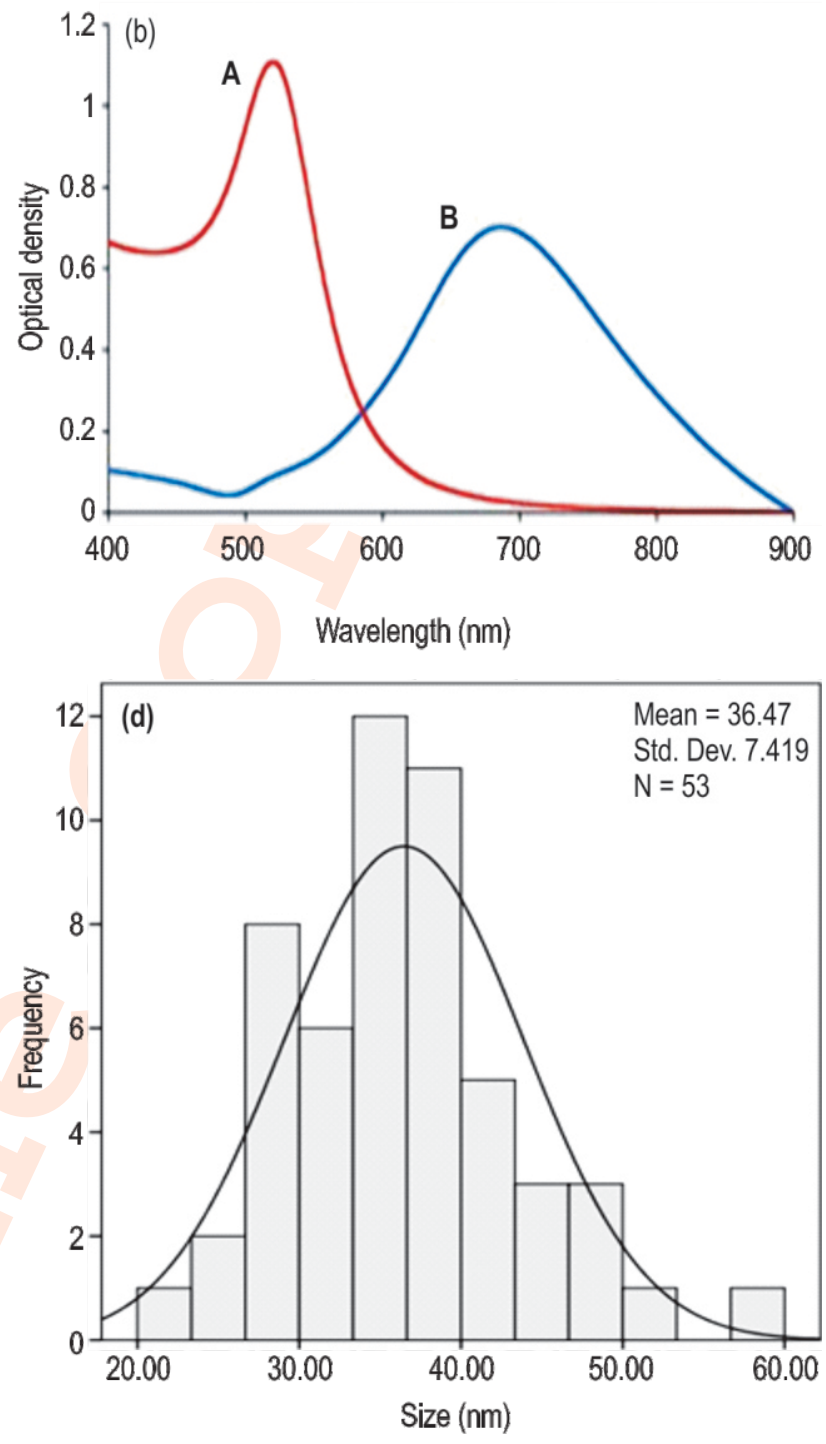

Fig. 1 : Characterization of gold nanoparticles (AuNPs): (a) Visual appearance of $40 \mathrm{~nm}$ diameter of colloidal AuNPs; and (b) UV-VIS spectra of $40 \mathrm{~nm}$ diameter of colloidal AuNPs Spherical (A) and urchin-shaped (B); (c) Transmission electron microscopy image shows that AuNPs exhibithomogeneous distribution in size and (d) Size distribution chart.

Table 1: Hatching and survival rate of African catfish, C. gariepinus embryo and larvae exposed to different concentration of gold nanoparticle

\begin{tabular}{llllll}
\hline $\begin{array}{l}\text { Concentration } \\
\text { mgl }^{-1}\end{array}$ & $\begin{array}{l}\text { Incubation } \\
\text { period }(\mathrm{hr})\end{array}$ & Hatching rate (\%) & $\begin{array}{l}\text { Survival of embryo at } \\
\mathbf{4 8} \mathrm{hr} \text { of exposure }\end{array}$ & $\begin{array}{l}\text { Larvae survival at } \\
\mathbf{2 4} \mathrm{hr} \text { of exposure }\end{array}$ & $\begin{array}{l}\text { Larvae survival at } \\
\mathbf{4 8} \mathrm{hr} \text { of exposure }\end{array}$ \\
\hline 0 & 25 & $84.4 \pm 1.6^{\mathrm{a}}$ & $72.2 \pm 3.6^{\mathrm{a}}$ & $100 \pm 0.0^{\mathrm{a}}$ & $95.3 \pm 5.7^{\mathrm{a}}$ \\
0.1 & 25 & $83.2 \pm 4.5^{\mathrm{a}}$ & $66.3 \pm 5.4^{\mathrm{a}}$ & $94.4 \pm 2.5^{\mathrm{a}}$ & $31.9 \pm 2.9^{\mathrm{b}}$ \\
0.5 & 25 & $84.4 \pm 2.3^{\mathrm{a}}$ & $62.1 \pm 3.2^{\mathrm{a}}$ & $93.6 \pm 10.9^{\mathrm{a}}$ & $23.8 \pm 0.4^{\mathrm{c}}$ \\
1 & 25 & $89.5 \pm 4.4^{\mathrm{a}}$ & $62.3 \pm 2.4^{\mathrm{a}}$ & $88.6 \pm 9.6^{\mathrm{a}}$ & $25.2 \pm 4.5^{\mathrm{c}}$ \\
5 & 25 & $88.5 \pm 3.4^{\mathrm{a}}$ & $62.4 \pm 7.5^{\mathrm{a}}$ & $85.2 \pm 7.6^{\mathrm{a}}$ & $24.3 \pm 1.1^{\mathrm{c}}$ \\
10 & 25 & $83.9 \pm 8.6^{\mathrm{a}}$ & $57.7 \pm 16.5^{\mathrm{a}}$ & $83.2 \pm 8.3^{\mathrm{a}}$ & $5.4 \pm 2.5^{\mathrm{d}}$ \\
50 & 24 & $88.3 \pm 4.8^{\mathrm{a}}$ & $53.9 \pm 10.9^{\mathrm{a}}$ & $72.2 \pm 7.2^{\mathrm{b}}$ & $7.9 \pm 2.0^{\mathrm{d}}$ \\
100 & 22 & $77.1 \pm 4.9^{\mathrm{b}}$ & $52.4 \pm 11.4^{\mathrm{a}}$ & $16.7 \pm 5.9^{\mathrm{c}}$ & 0 \\
\hline
\end{tabular}

Each value is mean of three replicates $\pm S D$ and the values in the column bearing different superscripts are statistically significant $(P<0.05)$. 
$100 \%$ larval mortality at the highest concentration $\left(100 \mathrm{mgl}^{-1}\right)$ was observed. Overall, the findings indicated time- and dosedependent survival rate of the embryo and larvae exposed to AuNPs.

Malformations in the embryos after exposure to AuNPs : A number of malformations were noticed in AuNPs exposed groups and the abnormalities observed are shown in Fig. 2. Typical malformations included irregular head shape, lordosis, yolk sac edema, body arquation, skin ulceration, pericardial edema and haemorrhage pericardial. The observations revealed pericardial edema and lordosis as the most significant malformations among the AuNPs exposed embryos.

The use of nanomaterials is widespread, especially in consumer products that are used for daily life. Silver and gold nanoparticles are widely used among the nanoparticles available. Their use in products such as washing machines, personal care products, and clothing leads to accumulation in sewage treatment plants and ultimately the aquatic environment. Nanomaterial contaminants have detrimental effects on human health and the environment despite their useful applications. The toxicity of nanoparticles has been documented in aquatic organisms, especially in fish (Kashiwada, 2006). Chi et al. (2009) revealed the toxic effect of nanoparticles at a gene and protein molecular level. The toxicity of AuNPs towards a wide range of aquatic organisms from plants to vertebrates has been reported. These include aquatic plants, freshwater algae, blue mussel, Mytilus edulis and zebrafish (Dedeh et al., 2015; Lapresta Fernanandez et al., 2012).

Nanoparticles' toxicity varies depending on the size, charge, and bioavailability of nanoparticles. Therefore it is recommended that nanomaterials be described in-depth prior to the toxicity study in order to achieve a better understanding of the toxicity experiments (Balbus et al., 2007; Li et al., 2011). In this study, two differently shaped AuNPs characterized were spherical and urchin shaped. However, only spherical shaped AuNPs were used for TEM and toxicity assays. TEM was utilized to determine the morphology and size of the particles. Moreover, most of the AuNPs that were dissolved in water became aggregated and settled down within $24 \mathrm{hr}$, thus the incubation medium was clear and transparent. A similar observation was reported by Lee and Ranville (2012), where AuNPs aggregated and settled in nanoparticle mixed water within $24 \mathrm{hr}$. They also reported that only negatively charged AuNPs aggregated and settled down. Thus, it is clear that the spherical shaped AuNPs with an optimum size of $36.47 \mathrm{~nm}$ used in this study for the toxicity assays were negatively charged and relatively more aggregated.

Most studies indicate that AuNPs are not cytotoxic and some that they minimize production of ROS (Connor et al., 2005; Khan et al., 2007; Shukla et al., 2005). Nonetheless, few studies have suggested that nano-metals can cause a wide range of sub-

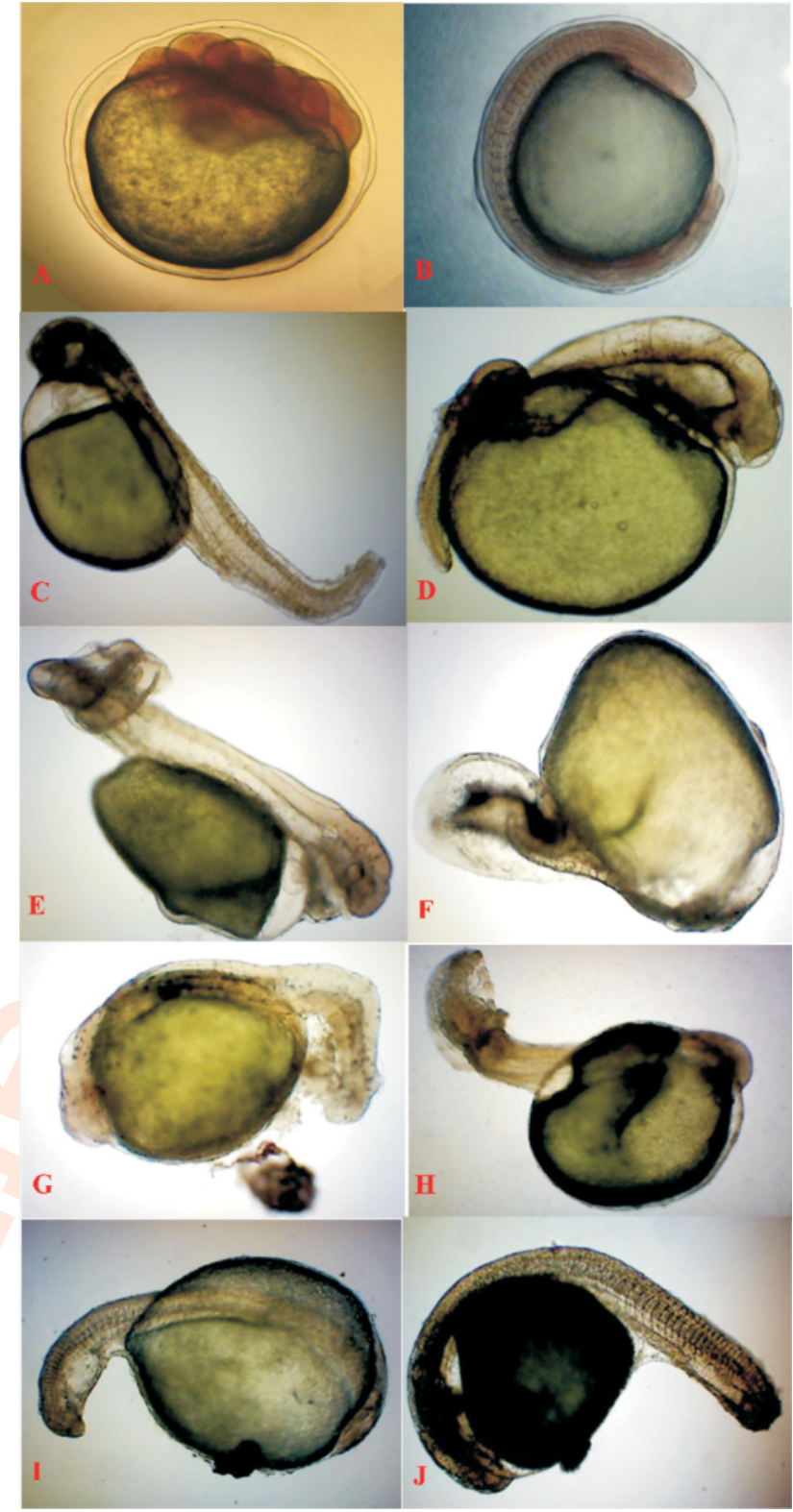

Fig. 2 : Malformations (irregular head shape, lordosis, yolk sac edema, body arcuation, tissue ulceration, pericardial edema and pericardial hemorrhage) induced by AuNPs. (A) 8 cell stage embryo from control treatment; (B) Embryo from control treatment; (C) Hatchling with tail curvature and pericardial edema exposed to $0.5 \mathrm{mg} \mathrm{l}^{-1}$; (D) Hatchling with irregular head shape and lordosis exposed to $0.5 \mathrm{mg} \mathrm{l}^{-1} ;(\mathrm{E})$ Notochordal abnormality (body curvature) lordosis exposed to $1 \mathrm{mg} \mathrm{I}^{-1}$; (F) Yolk sac edema and body arcuation exposed to $5 \mathrm{mg} \mathrm{l}^{-1} ;(\mathrm{G})$ Hatchlings with scoliosis exposed to $10 \mathrm{mg} \mathrm{l}^{-1} ;$ (H) Yolk sac edema and body arcuation with short tail exposed to $50 \mathrm{mg} \mathrm{I}^{-1}$; (I) Hatchling with bag shaped yolk sac with skeletal flexure and vertebral truncation exposed to $100 \mathrm{mgl}^{-1}$ and $(\mathrm{J})$ Hatchling with pericardial edema exposed to $100 \mathrm{mg} \mathrm{l}^{-1}$.

lethal effects in fish, including breathing toxicity, tissue trace element disruptions $\mathrm{Na}(+) \mathrm{K}(+)$-ATPase, inhibition and oxidative stress. In a variety of organs including gill, liver, intestine, and 
brain, nano metals have also induced organ pathologies. Toxicity of nanoparticles is more pronounced, especially at embryo and larval stages. The intake of nanoparticles by embryo is more than that of larval stage. Toxicity assays performed in cell lines are reliable; however, toxicity differs between artificial cell lines and live animals. Developmental toxicity of AuNPs cannot be determined in a human embryo; hence a better animal model is necessary to elucidate the toxic effects of AuNPs.

The results of the study showed that African catfish embryos and larvae, exposed to AuNPs showed significant decrease in hatching and survival rate in a dose- and timedependent manner. Lordosis and body arcuation malformations are referred as excessive inward curvature of lumbar and cervical regions of the spine accompanied by abnormal calcification of afflicted vertebrae (Dickson, 2004). These malformations were observed in most of the treated embryos, especially at high concentrations of AuNPs. Similar effects were observed in zebrafish embryos exposed to silica nanoparticles, where embryo and larvae malformations and mortality had increased, leading to embryonic developmental toxicity that alters larval locomotive activity (Duan et al., 2013). The present findings clearly implicate that AuNPs are toxic to catfish embryos and larvae; however, the mode of AuNPs toxicity in embryo and larvae of catfish is not yet elucidated. In conclusion, $24 \mathrm{hr}$ exposure to AuNPs triggered embryonic developmental toxicity, leading to severe effects on larval survival. Consequently, the results indicate that exposure to AuNPs can pose a potential risk to aquatic organisms. Therefore, further studies are needed for early embryonic and larval studies and safety assessment of AuNPs on the relationship between exposure, adverse effects and biological mechanisms.

\section{References}

Aillon, K.L., Y. Xie, N. El-Gendy, C.J. Berkland and M.L. Forrest: Effects of nanomaterial physicochemical properties on in vivo toxicity. $A d v$. Drug Deliv. Rev., 61, 457-466 (2009).

Almeida, J.P.M., A.L. Chen, A. Foster and R. Drezek: In-vivo biodistribution of nanoparticles. Nanomedicine (London, England), 6, 815-835 (2011).

APHA: Standard Methods for the Examination of Water and Wastewater. Washington DC:American Public HealthAssociation (2012).

Azzazy, H.M.E. and M.M.H. Mansour: In vitro diagnostic prospects of nanoparticles. Clin. Chim. Acta., 403, 1-8 (2009

Boisselier, E. and D. Astruc: Gold nanoparticles in nanomedicine: Preparations, imaging, diagnostics, therapies and toxicity. Chem. Soc. Rev., 38, 1759 (2009).

Boudreau, M., S.C, Courtenay, D.L. MacLatchy, C.H. Bérubé, J.L. Parrott and G.J. Van der Kraak: Utility of morphological abnormalities during early-life development of the estuarine mummichog, Fundulus heteroclitus, as an indicator of estrogenic and antiestrogenic endocrine disruption. Environ. Toxicol. Chem., 23, 415-425 (2004).

Bracamonte, M.V., S. Bollo, P. Labbé, G.A. Rivas and N.F. Ferreyra: Quaternized chitosan as support for the assembly of gold nanoparticles and glucose oxidase: Physicochemical characterization of the platform and evaluation of its biocatalytic activity. Electrochim. Acta., 56, 1316-1322 (2011).

Brandenberger, C., B. Rothen-Rutishauser, C. Mühlfeld, O. Schmid, G.A. Ferron, K.L. Maier, P. Gehr and A.G. Lenz: Effects and uptake of gold nanoparticles deposited at the air-liquid interface of a human epithelial airway model. Toxicol. Appl. Pharmacol., 242, 56-65 (2010).

Chandra, P., D. Das and A.A. Abdelwahab: Gold nanoparticles in molecular diagnostics and therapeutics. Digest J. Nanomat. Biostruct., 5, 363-367 (2010).

Chi, Z., R. Liu, L. Zhao, P. Qin, X. Pan, F. Sun and X. Hao: Anew strategy to probe the genotoxicity of silver nanoparticles combined with cetylpyridine bromide. Acta Part A Mol. Biomol. Spectrosc., 72, 577-581 (2009).

Chithrani, B.D., A.A. Ghazani and W.C.W. Chan: Determining the size and shape dependence of gold nanoparticle uptake into mammalian cells. Nano Lett., 6, 662-668 (2006).

Connor, E.E., J. Mwamuka, A. Gole, C.J. Murphy and M.D. Wyatt: Gold nanoparticles are taken up by human cells but do not cause acute cytotoxicity. Small., 1, 325-327 (2005).

Dedeh, A., A. Ciutat, M. Treguer-Delapierre and J.P. Bourdineaud: Impact of gold nanoparticles on zebrafish exposed to a spiked sediment. Nanotoxicology, 9, 71-80(2015).

Lapresta Fernanandez, A., A. Fernandez and J. Blasco: Nanoecotoxicity effects of engineered silver and gold nanoparticles in aquatic organisms. Trends Anal. Chem., 32, 40-59 (2012).

Dickson, R.A.: Spinal deformity basic principles. Curr. Orthop., 18, 411-425 (2004).

Dreaden, E.C., A.M. Alkilany, X. Huang, C.J. Murphy and M.A. El-Sayed: The golden age: Gold nanoparticles for biomedicine. Chem. Soc. Rev., 41, 2740-2779 (2012).

Duan, J., Y. Yu, H. Shi, L. Tian, C. Guo, P. Huang and Z. Sun: Toxic effects of silica nanoparticles on zebrafish embryos and larvae. PloS ONE, 8, e74606 (2013).

Fadeel, B. and A.E. Garcia-Bennett: Better safe than sorry: Understanding the toxicological properties of inorganic nanoparticles manufactured for biomedical applications. Adv. Drug Deliv. Rev., 62, 362-374 (2010).

Fraysse, B., R. Mons and J. Garric: Development of a zebrafish 4-day embryo-larval bioassay to assess toxicity of chemicals. Ecotoxicol. Environ. Saf., 63, 253-267 (2006).

Frens, G.: Controlled nucleation for the regulation of the particle size in monodisperse gold suspensions. Nat. Phys. Sci., 241, 20-22(1973).

Hashmi, A.S.K. and G.J. Hutchings: Gold Catalysis. Angew. Chemie Int. Ed., 45, 7896-7936 (2006).

Jenkins, J.T., D.L. Halaney, K.V. Sokolov, L.L. Ma, H.J. Shipley, S. Mahajan and M.D. Feldman: Excretion and toxicity of gold-iron nanoparticles. Nanomedicine Nanotechnology, Biol. Med., 9, 356-365 (2013).

Kashiwada, S.: Distribution of nanoparticles in the see-through medaka (Oryzias latipes). Environ. Health Perspect., 114, 1697-1702 (2006).

Khan, J.A., B. Pillai, T.K. Das, Y. Singh and S. Maiti: Molecular effects of uptake of gold nanoparticles in HeLa cells. Chem Bio Chem., 8 , 1237-1240 (2007).

Khlebtsov, N. and L. Dykman: Biodistribution and toxicity of engineered gold nanoparticles: A review of in-vitro and in-vivo studies. Chem. 
Soc. Rev., 40, 1647-1671 (2011).

Lee, B.T. and J.F. Ranville: The effect of hardness on the stability of citrate-stabilized gold nanoparticles and their uptake by Daphnia magna. J. Hazard. Mater., 213-214, 434-439 (2012).

Lewinski, N., V. Colvin and R. Drezek: Cytotoxicity of nanoparticles. Small., 4, 26-49 (2008).

Li, Y., L. Sun, M. Jin, Z. Du, X. Liu, C. Guo and Z. Sun: Size-dependent cytotoxicity of amorphous silica nanoparticles in human hepatoma HepG2 cells. Toxicol. Vitr., 25, 1343-1352 (2011).

Longmire, M., P.L. Choyke and H. Kobayashi: Clearance properties of nano-sized particles and molecules as imaging agents: considerations and caveats. Nanomedicine, 3, 703-717 (2008).

Marimuthu, K., N. Muthu, R. Xavier, J. Arockiaraj, M.A. Rahman and S. Subramaniam: Toxicity of buprofezin on the survival of embryo and larvae of African catfish, Clarias gariepinus (Bloch). PLOS ONE, 8, (2013).

Marsich, E., A. Travan, I. Donati, A. Di Luca, M. Benincasa, M. Crosera and S. Paoletti: Biological response of hydrogels embedding gold nanoparticles. Colloids and Surf B: Biointerfaces., 83, 331-339 (2011)..

McPherson, J.S. and D.T. Thompson: Selectivity of gold catalysts for applications of commercial interest. Top. Catal., 52, 743-750 (2009).

Michael, W.H., D. Amala, S.W. Peter, M.H. Kennedy and W. Murray: Crystal structure of the gold nanoparticle $\left[\mathrm{N}\left(\mathrm{C}_{8} \mathrm{H}_{17}\right)_{4}\right]$ $\left[\mathrm{Au}_{25}\left(\mathrm{SCH}_{2} \mathrm{CH}_{2} \mathrm{Ph}\right)_{18}\right]$, J.Am. Chem. Soc., 130, 3754-3755 (2008).

Nimesh, S., N. Gupta and R. Chandra: Cationic polymer based nanocarriers for delivery of therapeutic nucleic acids. J. Biomed. Nanotechnol., 7, 504-520 (2011).

Oberdorster, G., E. Oberdorster and J. Oberdörster: Nanotoxicology: an emerging discipline evolving from studies of ultrafine particles. Environ. Hlth. Perspect., 113, 823-839(2005).

Ostroumov, S.A., V.A. Poklonov, S.V. Kotelevtsev and S.N. Orlov: Toxicity of gold nanoparticles for plants in experimental aquatic system. Moscow Univ. Biol. Sci. Bull., 69, 108-112 (2014).

Pan, Y., S. Neuss, A. Leifert, M. Fischler, F. Wen, U. Simon and W. Jahnen-Dechent: Size-dependent cytotoxicity of gold nanoparticles. Small., 3, 1941-1949 (2007).

Pernodet, N., X. Fang, Y. Sun, A. Bakhtina, A. Ramakrishnan, J. Sokolov and M. Rafailovich:Adverse effects of citrate/gold nanoparticles on human dermal fibroblasts. Small., 2, 766-773 (2006).

Peters, L.E., M. MacKinnon, T.V. Meer, M.R. Van den Heuvel and D.G. Dixon: Effects of oil sands process-affected waters and naphthenic acids on yellow perch (Perca flavescens) and Japanese medaka (Oryzias latipes) embryonic development. Chemosphere, 67, 2177-2183(2007).

Pissuwan, D., T. Niidome and M.B. Cortie: The forthcoming applications of gold nanoparticles in drug and gene delivery systems. J. Control. Release., 149, 65-71 (2011).

Prime, D., S. Paul and P.W. Josephs Franks: Gold nanoparticle charge trapping and relation to organic polymer memory devices. Philos. Trans. R. Soc. AMath. Phys. Eng. Sci., 367, 4215-4225 (2009).

Sardar, R., A.M. Funston, P. Mulvaney and R.W. Murray: Gold Nanoparticles: Past, Present and Future. Langmuir., 25, 13840-13851(2009).

Shen, W., X. Zhang, Q. Huang, Q. Xu and W. Song: Preparation of solid silver nanoparticles for inkjet printed flexible electronics with high conductivity. Nanoscale., 6, 1622-1628 (2014)..

Shukla, R., V. Bansal, M. Chaudhary, A. Basu, R.R. Bhonde and M. Sastry: Biocompatibility of gold nanoparticles and their endocytotic fate inside the cellular compartment: A microscopic overview. Langmuir., 21, 10644-10654 (2005).

Tedesco, S., H. Doyle, J. Blasco, G. Redmond and D. Sheehan: Oxidative stress and toxicity of gold nanoparticles in Mytilus edulis. Aquat. Toxicol., 100, 178-186 (2010).

Tedesco, S., H. Doyle, G. Redmond and D. Sheehan: Gold nanoparticles and oxidative stress in Mytilus edulis. Mar. Environ. Res., 66, 131-133 (2008).

Tsoukalas, D.: From silicon to organic nanoparticle memory devices. Philos. Trans. R. Soc. A Math. Phys. Eng. Sci., 367, 4169-4179 (2009)..

Turkevich, J., P.C. Stevenson and J. Hillier: A study of the nucleation and growth processes in the synthesis of colloidal gold. Discuss. Faraday Soc., 11, 55 (1951).

Westernhagen, H.V.: Sublethal effects of pollutants on fish eggs and larvae. Fish Physiol., 11, 253-346 (1988).

Yih, T.C. and M. Al-Fandi: Engineered nanoparticles as precise drug delivery systems. J. Cell. Biochem., 97, 1184-1190 (2006).

Zhang, X.D., H.Y. Wu, D. Wu, Y.Y. Wang, J.H. Chang, Z.B. Zhai and F.Y. Fan: Toxicologic effects of gold nanoparticles in-vivo by different administration routes. Int. J. Nanomedicine, 5, 771 (2010).

Zhu, X., L. Zhu, Z. Duan, R. Qi, Y. Li and Y. Lang: Comparative toxicity of several metal oxide nanoparticle aqueous suspensions to Zebrafish (Danio rerio) early developmental stage. J. Environ. Sci. Heal. PartA., 43, 278-284(2008). 